\title{
Educators' perceptions of mathematically gifted students and a socially supportive learning environment - A case study of a Finnish upper secondary school
}

\author{
Eeva Haataja, Anu Laine and Markku S. Hannula \\ Department of Education, University of Helsinki, Finland
}

This article explores five educators' conceptions of the characteristics of mathematically gifted students and a social learning environment that supports their development in a school for mathematically gifted adolescents in Finland. We conducted this qualitative study through semi-structured interviews and participant observations in a Finnish upper secondary school with a special mathematics program. The research shows that gifted students and their educators form a tight community, the social learning environment of which supports shared motivation, healthy perfectionism, and practicing social skills. The results deepen the understanding of gifted education in the Finnish context and the significance of educators' shared understanding of social activities as a basis for successful gifted education.

Keywords: mathematical giftedness, qualitative case study, social learning environment, secondary education

\author{
Article Details \\ LUMAT General Issue \\ Vol 8 No 1 (2020), 44-66 \\ Received 7 October 2019 \\ Accepted 24 April 2020 \\ Published 1 June 2020 \\ Pages: 23 \\ References: 43 \\ Correspondence: \\ eeva.haataja@helsinki.fi \\ https://doi.org/10.31129/ \\ LUMAT.8.1.1368
}

\section{Introduction}

A gifted adolescent's school environment is a complex and continuously changing network of several actors and different forms of relationships (Ziegler \& Stoeger, 2017). In their research review, Thapa, Cohen, Guffey, and Higgins-D’Alessandro (2013) define five dimensions of beneficial school climate: safety, relationships, teaching and learning, institutional environment, and improvement process. By improving these dimensions, educators can create a positive environment in their schools and significantly influence their students' social-emotional wellbeing, motivation, and learning outcomes (Thapa et al., 2013). To examine the educators' conceptions of the social aspects of school in Finnish gifted education, this research focuses on social relationships, which Thapa et al. (2013) describe as connectedness between people in the school community.

The significance of relationships is also apparent in Gagnés (2015) definition of talent development as a process of advancing natural abilities to high competence. This development is influenced by two types of catalysts: the student's intrapersonal characteristics (e.g., motivation, perfectionism) and the surrounding environment 
(e.g., peer relationships) (Gagné, 2015), which are in continuous interaction (Ziegler \& Stoeger, 2017).

Previous research has highlighted the significance of a sensitive and dedicated teacher for the collective learning of gifted students and the need for charting pedagogical practices that can support a community of gifted students (Kuusisto \& Tirri, 2015). To investigate what makes a beneficial social learning environment for gifted education in a Finnish school community of mathematically gifted adolescents, this study examines educators' conceptions of the characteristics of gifted students and the practical implications of the social learning environment in gifted education. We collected the data by interviewing five educators (three teachers, the school social worker, and the principal) who work with students of a special mathematics program.

\section{Mathematically gifted students}

Mathematical giftedness means the ability to master abstract numbers, variables and functions, and the relations between them. For a mathematically gifted person, talent development also requires courage, persistence, and intrinsic motivation to go further and deeper into such modes of comprehension (Reis \& McCoach, 2002; MovshovitzHadar \& Kleiner, 2009; Subotnik et al., 2009). A mathematically gifted and wellperforming upper secondary school student is well on her way to becoming a member of the domain of mathematics (Cross \& Coleman, 2014). She has developed an indepth understanding of the mathematical concepts studied at school, and is committed to studying hard (Subotnik et al., 2009) and, with the support of her surroundings, is able to play an active role in her own learning (Cross \& Coleman, 2014; Usiskin, 2000).

A gifted person is only able to fulfill her whole potential if her intrinsic characteristics and surrounding environment are in balance (Subotnik, Pillmeier, \& Jarvin 2009; Usiskin, 2000). Mathematically gifted adolescents need intrinsic motivation to study and adequate social skills to be part of a peer group, express their mathematical insights and seek guidance when needed (Mann, 2006; Subotnik et al., 2009). Sharing the learning environment with other gifted students affects their motivation and social relationships (Plucker \& Dilley, 2016). The following sections of this paper investigate these aspects and combine the viewpoints of gifted education and social learning environment. 


\subsection{Supporting the motivation of gifted students}

Teachers' conceptions affect the development of gifted students (McNabb, 2003). Therefore, these conceptions play a significant role in helping young gifted students advance their talent (Mann, 2006; Pettersson, 2008). Several studies have shown that teachers relate giftedness to motivation to learn quickly, intelligently, and creatively (Kaya, 2015; Laine, Kuusisto, \& Tirri, 2016; Mattsson, 2010; Moon \& Brighton, 2008). One study of Swedish teachers saw motivation as including persistence and enjoyment of mathematics (Mattsson, 2010). However, the participants found it difficult to motivate mathematically gifted students if they were not used to persistent studying (Mattsson, 2013).

High-level learning is fundamental for talent development (Gagné, 2015) and requires a proper motivational structure that enhances the beneficial attributes of failure and success (Heller, 2013). Some gifted people possess perfectionistic traits, which can either enhance or restrict positive talent development. Healthy, adaptive perfectionism offers satisfaction from high-level learning and sustains motivation to learn more, whereas unhealthy, maladaptive perfectionism has the opposite effect (Basirion, Majid, \& Jelas, 2014). The orientation of perfectionism can vary from positive pursuit of excellent learning to unhealthy comparison to surrounding peers (Speirs Neumeister, 2016; Stoeber, 2014).

Teachers can support healthy perfectionism in their school community (Basirion et al., 2014). According to teachers' perceptions, collaborative learning, and shared goals positively influence students' relationships by enhancing connectedness and trust (Thapa et al., 2013). Together with adequately challenging instruction (Brigandi, Weiner, Siegle, Gubbins, \& Little, 2018; Speirs Neumeister, 2016), this feeling of connectedness helps gifted students focus their perfectionism on positive striving (Basirion et al., 2014; Stoeber, 2014). Informal learning and out-of-school activities such as summer schools may provide opportunities for collaborative learning with congenial peers and thus support the wellbeing of gifted adolescents (Koichu \& Andzans, 2009; McHugh, 2006; Winkler, Stephenson, \& Jolly, 2012).

According to Ziegler and Phillipson's (2012) systemic theory of gifted education, the social, emotional, and structural context of a gifted student affects their talent development. As the development of individual talent takes unique paths (Cross \& Coleman, 2014), it is important to investigate the values, relationships, and practices of the whole school community (Ziegler \& Phillipson, 2012). 


\subsection{Supporting relationships of gifted students}

Positive relationships between individuals in the school community can be seen in, for example, the sense of connectedness and respect for different personalities (Thapa et al., 2013). According to Finnish teachers, the most determining characteristic of gifted students in the school context is their specific difference from others (Laine et al., 2016). Several studies in different cultures show that dissimilarity and even unpopularity may be challenges for gifted adolescents among their age group (Cross, 2016; Cross \& Cross, 2015; Mönks \& van Boxtel, 1985), especially when one is gifted in mathematics (Pettersson, 2008).

To prevent possible isolation of gifted adolescents, and to encourage them to develop their giftedness, the school community should receive guidance in creating supportive peer relationships (Cross, 2016; Cross \& Cross, 2015). Support of congenial peers is essential for talent development (Brigandi et al., 2018; Muratori et al., 2006). Learning social skills in a beneficial learning environment constructs a basis for creating egalitarian friendships (Cross, 2016), but also for development towards successful professional mathematical performance (Cross \& Coleman, 2014). Highly mathematically gifted girls, in particular, seem to benefit from a supportive school environment (Heller, 2013).

It is interesting to note that Nordic teachers mainly associate positive socialemotional characteristics such as enthusiasm, sensitivity, and curiosity with giftedness (Kaya, 2015; Laine et al., 2016; Mattsson, 2010). In general, gifted students are seen as well-behaving, well-managing independent learners (Kaya, 2015; Mattsson, 2010; Moon \& Brighton, 2008).

\section{Conceptions of giftedness among educators in Finland}

Public and personal conceptions of giftedness (Speirs Neumeister, 2016), as well as the needs of the gifted students themselves (Pfeiffer \& Burko, 2016), vary across cultures. In Finland, special education of the gifted is still rare and focuses mainly on academic achievement, although the Ministry of Education of Finland acknowledged the need for the social-emotional education of gifted students already in 2010 (Tirri \& Kuusisto, 2013). In the Nordic countries, the purpose of the school system is to enhance egalitarianism in society (Mattsson, 2013). These egalitarian objectives emphasize a shared assumption of similarity and coherence in society and the avoidance of embracing extremes in people's achievements and goals (Persson, 2014). 
As a result, Nordic public discourse (Laine, 2010; Persson, 2011) and educators' conceptions of giftedness (Mattsson, 2013) lack coherent definitions and interest in intellectual giftedness (Laine, 2010; Mattsson, 2013; Persson, 2011). As an example, Finland's normative National Core Curriculum for General Upper Secondary Schools (Finnish National Agency for Education, 2015) offers no guidance on gifted education, and the current Core Curriculum for Basic Education (Finnish National Agency for Education, 2014) is the first to even mention talented students.

Laine, Kuusisto, and Tirri (2016) investigated Finnish teachers' conceptions of giftedness and noticed superficiality and inconsistency among them. According to the study, many teachers still define giftedness as a fixed, natural characteristic of a person. Some teachers even believe that gifted students do not need training or instruction. The research also shows a gap between teachers' conceptions and the practices of gifted education (Laine et al., 2016).

\section{Research question}

The purpose of this study was to examine educators' conceptions of a social learning environment that can support the social-emotional needs of mathematically gifted adolescents. Our research question is:

How do the educators of a Finnish upper secondary school with a special mathematics program describe their students' giftedness and the school's practices to promote a positive social learning environment?

\section{Method}

Only five of Finland's 342 upper secondary schools (optional general education grades 10-12 after compulsory basic education, for adolescents aged 16-18) offer an official special mathematics program. One of these was the case in this study. The conceptions of gifted education held by the educators of the school were explored through semistructured interviews.

\subsection{School context}

The school's special program was founded in 1995, whereas the history of the school dates back to the 1920s. The school is a private upper secondary school in a large city. In Finland, even private schools are government-funded, with no fees for the students. 
However, as a private school, this school has its own administration and curriculum, which has to be aligned with the National Core Curriculum for Upper Secondary Schools (Finnish National Board of Education, 2003, at the time of the study). According to the school's current 2016 curriculum, the purpose of the school is to enhance the mathematical skills of Finnish adolescents.

The special mathematics program students belong to the larger school community of approximately 800 lower and upper secondary school students and approximately 30 upper secondary school teachers. Approximately 100 students of both genders study the special mathematics program, divided into three classes according to their initial year. The selection of students for the mathematical program is based on an entrance examination and their final grades in the academic subjects of basic education. According to the principal's interview (Interview 2, February 9, 2012), the school wishes to find students who possess a good knowledge of mathematical content taught in basic school but also a strong motivation to learn more. As is common in Finland, measurements of giftedness or intelligence are not in use in this school.

The school offers a wide range of instruction in mathematics. In addition to the fourteen national compulsory courses, students can study up to twenty extra courses, ranging from the history of mathematics to the results of recent mathematical research. Furthermore, the school offers diverse learning environments through a variety of informal teaching methods. For example, the Night of Mathematics is an overnight activity at the school's premises every January and September, and the Lapland summer school is an annual summer camp in Northern Finland, which combines informal mathematics learning and experiential biology education in nature. The school also arranges courses in cooperation with a university as well as practice camps for the International Mathematical Olympiad. The biology teacher (Interview 4, February 14, 2012) estimated that after the matriculation examination, $80 \%$ of the students of the special mathematics program proceed to studies in mathematical domains.

\subsection{Participants}

We collected the data by interviewing three teachers, the principal, and the school social worker, and by observing an overnight school activity. The researcher first contacted Mathematics Teacher 1 (Interview 1, February 9, 2012), who responded by expressing interest in this research. With the principal's permission, five educators volunteered for an interview. The students were informed of the researcher's 
observation in advance. All research participants (educators and students) gave their consent for the study.

These particular interviewees were selected to provide a comprehensive and diverse picture of the education of the gifted in this school from a specific viewpoint. The mathematics teachers were able to offer insights into mathematical giftedness and the mathematics education of the school. Mathematics Teacher 1 was the headteacher of the special program and assisted the principal in administrative work. He was also a former student of the school and had worked in the school as a parttime teacher during his university studies since 2003 and in a full-time position for five years. With his help, the researcher chose the rest of the interviewees. Mathematics Teacher 2 (Interview 3, February 14, 2012) had taught both lower and upper secondary school students for six years at the school. At the time of the data collection, Mathematics Teacher 2 had participated in the Lapland summer school twice. Mathematics Teacher 1 recommended interviewing the biology teacher (Interview 4, February 14, 2012) due to her experience in teaching the students of the special program: She had worked at the school for 27 years, attended 15 summer camps, and been involved in the establishment process of the special mathematics program in the 1990 .

The school social worker (Interview 5, February 28, 2012) and principal (Interview 2, February 9, 2012) were interviewed to gain a comprehensive picture of the topic. The school social worker had worked as an elementary school teacher prior to starting in this position in 2002. She worked as a counselor for the students and helped them with challenges related to their studies and general wellbeing. Her clients mostly consisted of basic education students, but she also worked with the students in the special mathematics program. The principal was the head of the whole school community. She was a qualified Finnish language teacher and had worked in the school for over 20 years as a teacher and for three years as the principal. She had also contributed to the establishment of the special mathematics program. 


\subsection{Procedure}

Table 1 presents the study's data collection process and inductive content analysis.

Table 1. Procedural phases of data collection

\begin{tabular}{ll}
\hline 1 & Getting acquainted with the research case: \\
& Observations in overnight school and mathematics lessons and informal discussion \\
& with Mathematics Teacher 1 \\
\hline 2 & Creating research questions according to observation perceptions and literature: \\
& How do the educators of a Finnish upper secondary school with a special \\
& mathematics program describe their students' giftedness and the school's practices \\
& to promote a positive social learning environment? \\
\hline $3 \quad$ & Creating the interview frame (for whole frame, see Appendix): \\
& Question categories: Mathematical giftedness, Students of the school, Teaching, \\
& Practices \\
& An example question from the Practices category: What are the objectives of the \\
& Lapland summer school? What do you do there?
\end{tabular}

The first author attended the overnight school (January 20, 2012) and engaged in the social and mathematics activities of the event. The researcher also followed two mathematics lessons during the fall semester of 2011. The observations were in the form of video-recordings and note-taking. As Gillham (2010) argues, participant observation through descriptive notes can be used for getting acquainted with a case. Our purpose was to provide background information for the interviews and to improve the trustworthiness of the interpretations of the interview material through the researcher's personal experience of the school environment and social activities.

To cover our research questions, we selected semi-structured interviews as our main data source. The interview frame was formulated on the basis of the observations in the school and the cited literature on the social-emotional development of gifted students. Interviewing the authorities of the case can offer both wide and profound context evidence (Gillham, 2010). The researcher interviewed each respondent individually in the school building once. The duration of the interviews varied from 40 to 80 minutes. A qualitative semi-structured interview technique was used in order to give the interviewees the possibility to conceptualize and describe the topic in the way they preferred (Newby, 2010; Bodgan \& Biklen, 2007).

First, the interviewees were asked briefly about their professional background. Second, the questions concerned the interviewees' conceptions of mathematics and mathematical giftedness. Third, the researcher asked the informants to describe their 
students' social and emotional skills, issues, and relationships. The fourth topic of the interviews included conceptions of education and teaching. The final topic was concerned with this particular school's education in practice, especially informal and experiential learning methods, such as the summer school in Lapland and the overnight school. The complete English translation of the interview framework is in the Appendix.

\subsection{Analysis}

The first author recorded and transcribed the interviews and analyzed them using inductive content analysis. We chose the inductive approach, as we wanted to cover both the individual characteristics and social practices of the needs and support of gifted students. Table 2 presents an example of the qualitative analysis: an excerpt from the interview of the biology teacher regarding the summer school.

Table 2. Example of the analysis process

The analysis of the biology teacher's reply to the example question: What are the
objectives of the Lapland summer school? What do you do there?
A whole statement: "But we are pretty silly there. Hey, let's try this. Okay, let's do it."
$\rightarrow$ A code: in Lapland the atmosphere allows teachers and students to act silly
$\rightarrow$ A subcategory: the teacher-student relationships in the Lapland summer school
$\rightarrow$ A category: the summer school supports the social-emotional development of the
students
$\rightarrow$ The main category: experiential education and informal learning supports social-
emotional development of the students.

We chose a whole statement as the unit of the analysis. We identified the whole statements by searching for all the replies to the research questions from the transcripts. Each whole statement included one thought, conception, or opinion, which varied from a couple of words to several sentences. First, we summarized these units into codes. After this, as is typical in inductive content analysis (Bodgan \& Biklen, 2007; Elo \& Kyngäs, 2008), we connected the codes concerning the same topics into subcategories and then categories. The two research questions directed the categorization of the categories into main categories and the interpretation of the findings in light of the theoretical background of the study. In this phase, we compared the words the participants used in the original data to the concepts in the literature. To increase the trustworthiness of this study, the authors reflected on the chosen categories and peer debriefing during all the phases of the analysis process. 
The names in this paper have been anonymized. However, because of the uniqueness of this research context in the Finnish school system, it is not possible to ensure the anonymity of the school or its teachers. The respondents granted their permission for this publication and were offered the opportunity to comment on its content. A preliminary analysis has been published in the proceedings of The Tenth Congress of the European Society for Research in Mathematics Education CERME10 (Haataja \& Laine, 2017).

\section{Results}

First, we discuss how the educators described their students' mathematical giftedness. In the interviews, the conceptions of giftedness and gifted students were somewhat intermingled. The main categories responding to this research question were the conception of mathematical giftedness, high motivation, perfectionism, and variation of social skills. Second, we examine the conceptions of the school's social learning environment and the practices to support it. The main categories responding to this research question were appreciation of uniqueness, shared motivation, healthy perfectionism, and supportive environment for learning social skills.

\subsection{Educators' conceptions of mathematically gifted students}

Identification of giftedness is not common in Finland, and the interviewees approached the giftedness of their students descriptively. The educators interviewed in this study generally described their students as gifted despite the absence of the concept in the school's curriculum or official objectives during the time of the interviews (Curriculum of the School, 2005).

The conception of mathematical giftedness. The educators defined mathematical giftedness as the ability to picture, learn, and remember mathematical structures rapidly and with clarity. The interviewees saw mathematical giftedness as innate, but as invariably changing and developing through motivated practice.

"Of course, they need some kind of giftedness. If someone is totally ungifted, he can't learn no matter how motivated he is. But with some kind of basic giftedness, you can go quite far." (Interview 3)

They described two types of giftedness apparent in the school: students with multiple talents and those with a single mathematically focused talent. Students with 
multiple talents were often interested in influencing societal matters and participating in students' social activities. Other students focused on one talent with a deep commitment to studying mathematical reasoning skills.

"Roughly speaking, there are those Renaissance talents who are widely gifted. And then those with a special talent, who could be gifted in any field but focus on the area of their deepest interest." (Interview 2)

High motivation. The mathematics teachers interviewed in this study emphasized the significance of motivation in talent development. The educators described that motivation and enjoyment of learning mathematics was an essential characteristic of gifted students.

"They [students] are very motivated. [...] And that is more determining than giftedness." (Interview 3)

"They [mathematics teachers and students] enjoy digging into mathematics." (Interview 2)

Perfectionism. A high level of motivation sometimes relates to unhealthy perfectionism. The interviewees described students at risk of unhealthy perfectionism either as those with multiple interests and the will to learn several subjects to high standards or as those with extreme interest and overly serious relationship with learning mathematics. The biology teacher and the school social worker had seen how achieving high objectives or failing to do so could cause stress and feelings of exhaustion.

"It [exhaustion] does not occur often, but someone every year [is affected]." (Interview 2)

"If studies don't go as planned, it can cause terrible stress." (Interview 4)

"Often, great giftedness and striving for perfection and achievements are a part of the personality. There is a risk of stress and fatigue and exhaustion." (Interview 5)

"Upper secondary school is quite a tough thing if one wants to do it properly. [If, for the student,] properly means that one studies four languages [...] and a hundred courses. [...] Many find that only that is the proper way.” (Interview 1)

Variation of social skills. According to the interviews, the students with a narrow focus on mathematical talent faced more challenges in terms of social skills 
than those talented in various domains. According to Mathematics Teacher 1, both "social sharks" with an excellent level of social skills and those who had "obvious problems in that respect" could be found among the students of the school.

"Some of them have very poor social skills. [...] It's often the case in this narrow domain of talent." (Interview 4)

"We have many who are fundamentally reserved as individuals, but most of them open up during upper secondary school.” (Interview 1)

\subsection{Educators' descriptions of the school's social learning environment}

The educators shared a strong vision of the tight community of their school. This was seen to arise from "the spirit of the school" (Interview 2) and from "basic human values" (Interview 5). The tight community was described as consisting of (a) the appreciation of uniqueness and (b) a meeting place for congenial adolescents.

"I think that it's built into the ideology of our school. I don't believe that we've written any socialization objectives for the students of the special mathematics program. It's built into the spirit of the school." (Interview 2)

"And the kind of basic human values that teachers have here. [...] When you have the courage to use your abilities, then you also have the courage to fail and hurl yourself into difficult subjects.” (Interview 5)

Appreciation of uniqueness. The interviewees underlined the appreciation of the uniqueness of their students instead of characterizing them as a homogenous group. They described the students' personalities, interests, social skills, and profiles of talent as being very individual. The uniqueness of these individuals formed the basis of the school community.

“I don't want to give any stereotyped answer here. I don't want to say that they are like this or like that." (Interview 2)

"We have a wide variety of personalities and a tight community, which means that it becomes a broad-minded community." (Interview 1)

The interviewees described their school community as a meeting place for mathematically gifted students who are, in some way, different from other adolescents. According to educators, many of the students had experiences and memories of feeling different and isolated during lower secondary school. Sometimes a change of school was essential for a gifted adolescent. 
"And we offer a community where you can discuss the Schrödinger equation during a break without being sneered at." (Interview 3)

"I just received a message in which the parents were grateful because it's been so important [for their child] to be encouraged, accepted in the group, and let himself be himself [in this school].” (Interview 4)

The interviews indicate that the opportunity to study and associate with other gifted students was considered one reason for the distinctive solidarity in the school. Even though the students varied in terms of their social skills, common interests made social interaction easier.

"To find congenial people. And I know how the teachers describe how they [the students] do experiments in, for example, physics lessons, the burning enthusiasm they show." (Interview 5)

The mathematics teachers found it important to create a safe, beneficial, social learning environment for their students, but their ultimate goal was to offer highquality mathematics education.

"I'm not a social skills coach. Essentially, I teach mathematics." (Interview 1)

"Of course, if someone misbehaves, I have to do something. But I think that we teach the subject [mathematics] to students of this age." (Interview 3)

The interviewees described that the social support of gifted students was based on a shared vision of appreciation of unique, mathematically gifted personalities. The following sections present the characteristics of the social learning environment, which were also seen as beneficial for the development of mathematical talent.

Shared motivation to learn mathematics. The interviewees highlighted the significance of peer support for maintaining motivation. The shared motivation and interest in mathematics was visible in the overnight school, where groups of students solved mathematical problems together and demonstrated amazing enthusiasm.

"The passion for [mathematics] creates good common things in the class [...] and among the students." (Interview 5)

"And also, the point that the other members of the group are diversely gifted as well; no one is the best at everything. That makes everyone seriously try." (Interview 1) 
The tight community of the school focused on studying, which contributed to learning at an advanced level. The mathematics teachers believed that learning could also be negatively influenced by strong solidarity between the students if the group identified with anti-school opinions. In these circumstances, success at school might become a social burden to a motivated student. However, a tight community with a positive attitude towards school can encourage even an unmotivated student to study harder. Thus, motivation is not merely the characteristic of a single student but also of a school community that develops through shared support and goals. "Social pressure can affect them one way or the other. In this school, it has more
positive effects. [Here] someone may feel shame for not succeeding, but in some
schools, it's shameful to succeed. [...] [Here] they encourage each other very
much to study." (Interview 3)
"If the group focuses on knowing and studying hard, it supports those who in
some other environment would lag behind and laze around." (Interview 1)

The teachers also underlined persistence and courage to address mathematical challenges. The mathematics teachers considered the teaching of study techniques and the importance of constant studying one of their most important tasks.

"Teaching how to study is the duty of all teachers. [...] The emphasis on the significance of [persistent] work is very important." (Interview 3)

"And it's excellent if I can say that the practice exam didn't go so well, and let's practice now." (Interview 1)

"Because after lower secondary school, many of them lack the culture of working hard. [...] But on the other hand, it's very important to experience success right at the beginning." (Interview 1)

Healthy perfectionism. The informal learning environments of the school enabled open discussions on social matters. The observations of the overnight school showed that the students were able to discuss their perfectionism. The conversation was humorous, and the participants laughed at their perfectionistic traits. According to the interviews, studying with other gifted students in a supportive school environment helped the adolescents construct their perfectionism in a realistic selfimage, as both people and mathematicians.

"It's easy to get perspective, [because] some students really are incredibly good. [...] It combats thoughts of whether I am the very best. Well, everyone knows that they're not. Nobody is the very best.” (Interview 1) 
The interviewees tended to see unhealthy perfectionism as a practical problem of the educational system rather than a problem of the gifted. Summing up the perceptions of the interviewees, the school social worker told us that educators could prevent and address unhealthy perfectionism by guiding the students being adaptive and offering them constant care.

"Flexibility and a flexible education system protect the path of the adolescents somehow. And also caring in particular, daily care." (Interview 5)

Supportive environment to practice social skills. According to the interviews, one important goal of the school was to teach acceptance of all kinds of personalities. To elaborate, one participant at the overnight school had brought his own computer with him and spent the whole evening playing alone, but in the same room with others.

"Of course, one can choose to enjoy small groups or solitude.” (Interview 1)

The practice of social skills in upper secondary mathematics education was seen to occur through group work and conversation, which were commonly used as teaching methods. The interviewees saw that encouraging the students to discuss the studied contents together was a crucial method of teaching social skills in their school.

"But when we work with [mathematical] problems that take several hours to solve, brainstorming is very good. And I try to encourage that.” (Interview 1)

"It starts in the classroom. [...] To make everyone communicate and work with others at least sometimes." (Interview 4)

According to the interviewees, the students of the school were able to form close relationships with each other. The class-based structure and diverse range of informal activities formed the basis for the development of friendships at the school. The biology teacher had noticed that collaborative learning helps students also create relationships beyond mental boundaries between age groups. The educators were proud of the school's practices, such as the overnight school, which supported the connectedness of different age groups and "conveyed traditions" (Interview 1) from previous students to freshmen. Overnight school was seen to offer an opportunity to associate with like-minded peers, make new friends and informally learn interesting mathematics. 
"And then across the groups of each grade, because they spend time together on Mondays [when extra courses in mathematics are taught] and at overnight schools, there are no [age] boundaries." (Interview 4)

"They go to the Olympics training in [another upper secondary school], so they are interwoven with them, too." (Interview 4)

"It [the overnight school] is a really great way to informally give good role models when you can say that these ten buddies [former students] were once in the finals of a mathematics competition.” (Interview 1)

When asked about the practice of the annual Lapland summer school, Mathematics Teacher 1 described its objectives as "fifty-fifty" academic and social. The summer school offered informal, experiential education in mathematics and biology and practiced social skills with other gifted students.

"These summer camps are, of course, about spending time together in [...] a beautiful environment with instructive tasks." (Interview 2)

The summer school affected the students as individuals and the relationships both among themselves and between the students and the teachers. According to the biology teacher, this influence was built through collaboration, connectedness, and outdoor experiences. The students had the opportunity to experience nature together, and the teachers directed them less than in the school environment. During the summer school, even the most introverted students tended to open up socially and get to know others.

"There, the students need each other's support and they have to work as a team. And at the same time, they share experiences with each other." (Interview 4)

"And sometimes those kinds of [introverted] students come there with us. [...] Then, when they are together long enough, they start to communicate more with others." (Interview 3)

"It's amazing to notice how they somehow gain self-confidence." (Interview 5)

According to the Biology Teacher and Mathematics Teacher 2, the summer school made it possible to break out of the roles of teacher and student by changing the forms of interaction, which led to relaxing and having fun.

"But we are pretty silly there. Like hey, let's try this? Okay, let's do it." (Interview 4) 
"I think they are somehow more relaxed. At least they seem to like it a lot." (Interview 3)

\section{Discussion}

The semi-structured interviews enabled the educators to freely describe their school according to their own conceptions. The analysis of these interviews offered two main findings. First, the educators' descriptions of mathematical giftedness reflected the Finnish educational context and public discourse. Secondly, the interviews underlined the significance of a positive school community.

This qualitative case study deepens our understanding of the relatively unexplored field of gifted education in Finland. The Finnish context explains the conceptual incoherence in the educators' descriptions of giftedness (Laine, 2010). Approximately half of the Finnish teachers see giftedness as something innate and fixed (Tirri \& Kuusisto, 2013; Laine et al., 2016). The interviewees of this study described giftedness as an innate characteristic of a student, but as malleable rather than fixed, and as developing in the school community. Finnish teachers also tend to associate gifted students with positive social-emotional characteristics (Laine et al., 2016). These educators had also noticed issues of unhealthy perfectionism and isolation among the gifted students. Still, the positive attitude towards giftedness, as well as the educators' enthusiasm and pride in their students, were easily discerned in the interviews. The amount and especially the quality of cooperation with gifted students have also previously been found to determine teachers' conceptions of and approaches to giftedness (Kaya, 2015), which is congruent with the results of this research.

Finnish public discourse sometimes discourages separating groups of gifted students from other students (Laine, 2010). Whereas the identification of gifted individuals is often the first step of formal gifted education (Ziegler \& Phillipson, 2012), in this school, it seemed to occur during studies at the school, as giftedness per se was not the eligibility requirement of applying. Instead, giftedness was seen to be present in the social learning environment and in the interaction between the members of the school community. This finding was aligned with the theory of systemic gifted education, according to which talent development occurs in the nexus of an individual and the environment (Ziegler \& Stoeger, 2017).

At the time of the data collection of this study, the social objectives of gifted education were not explicit in the school curriculum nor in the National Core Curriculum for Upper Secondary Schools (Finnish National Board of Education, 
2003). Instead, social learning was embedded in the teaching methods of mathematics education. Throughout the interviews, the educators referred to the school's unique character, which guided their practices. The practices supporting talent development included three significant aspects: maintaining a high level of shared motivation, supporting healthy perfectionism, and providing a supportive environment in which to practice social skills. These aspects of support shared the factor of relationships as a catalyst for talent development (Gagné, 2015). The interviewed educators emphasized that the social learning environment is formed by motivating, caring for, and supporting the relationships between unique personalities in school.

The concept of dissimilarity is frequently included in the definitions of giftedness and in the conceptions of giftedness commonly held by Finnish teachers (Laine et al., 2016). The gifted are seen as somehow, although often positively, differing from others (Shani-Zinovich \& Zeidner, 2009). Therefore, it is important to understand the difference between the conception of dissimilarity in the theoretical definitions on the one hand and the subjective experience of a gifted adolescent in relation to their peers on the other. Teachers who work with gifted students can, at least to a certain extent, grasp what it is like for the students to feel different. According to this research, these feelings may cause isolation, which can, however, be prevented by supporting connectedness in school.

The social learning environment was found to support connectedness if the strong motivation for high-level learning was appreciated, challenges of unhealthy perfectionism were confronted openly and flexibly, and opportunities to practice social skills were offered. The pedagogical practices presented in this study could also be applied in other educational contexts. We suggest broad pedagogical reflection when planning and conducting informal, out-of-school learning activities, to reach a shared vision of the values behind and objectives of these methods.

\subsection{Limitations and future recommendations}

The authors used both observation and interviews to obtain a comprehensive picture of the school's social learning environment. The observation of the school's overnight activity and mathematics lessons provided first-hand information to the researchers, who had been unfamiliar with the school community before the study. With these perceptions, the interviews became easier to analyze and interpret. Nevertheless, a longer period of participatory observation could have offered more profound 
information on the social interactions of the students. In the future, student or parent interviews would help construct a more systemic picture of the school's gifted students and social learning environment. The selection of the interviewees was based on the recommendation of the headteacher of the special program, Mathematics Teacher 1 in this report. We asked him to recommend colleagues who had the most experience in the mathematical education of the students of the special program. Choosing teachers of humanistic subjects or arts might have led to somewhat different research results and could serve as an enlightening topic for future research.

Comparing these results with similar results in other cultural contexts either in Finland (e.g., cultural minorities or other fields of giftedness) or in other countries would provide a more profound picture of the role of social practices in gifted education. The Finnish education system offers a research context in which gifted education is planned and conducted by individual school communities without the explicit regulation of the National Board of Education. This highlights the importance of the shared vision of gifted education among the educators of schools. Comparison of the conceptions of the social learning environment and gifted education with school communities in more standardized gifted education contexts might serve as a relevant topic for future research.

\subsection{Conclusion}

The preceding discussion directs back to the implications of the school context. The organization and the curriculum of national school systems should meet the needs of every student, including the gifted (Cross \& Coleman, 2014; Kaya, 2015). This study shows that opportunities to build close relationships with educators and other gifted people create a social learning environment that is supportive and motivating for all kinds of gifted individuals. Finnish teachers are highly qualified and skilled at differentiating learning content for both fast and slow learners (Laine et al., 2016). However, this research shows that even the most devoted and competent teacher cannot replace the need to meet, study with, and make friends with congenial peers.

Although the Finnish national core curriculum (Finnish National Agency for Education, 2015) does not provide schools with tools for arranging gifted education, the school community plays a role in defining the shared attitude towards gifted students' special needs. In this school, the community enabled academic and social everyday support for gifted individuals. The results of this study afford both ideas for 
practical implications for educators and evidence of the need to organize and reflect on gifted education on a national level in Finland.

\section{References}

Basirion, Z., Majid, R., \& Jelas, Z. (2014). Big Five personality factors, perceived parenting styles, and perfectionism among academically gifted students. Asian Social Science, 1O(4), 8-15. doi:10.5539/ass.v10n4p8

Brigandi, C. B., Weiner, J. M., Siegle, D., Gubbins, E. J., \& Little, C. A. (2018). Environmental Perceptions of Gifted Secondary School Students Engaged in an Evidence-Based Enrichment Practice. Gifted Child Quarterly, 62(3), 289-305. doi:10.1177/0016986218758441

Cross, J. R. (2016). Gifted children and peer relationships. In M. Neihart, S. I. Pfeiffer, \& T. L. Cross (Eds.), The social and emotional development of gifted children: What do we know? (2nd ed.), (pp. 41-54). Waco, TX: Prufrock.

Cross, J. R., \& Cross, T. L. (2015). Clinical and mental health issues in counseling the gifted individual. Journal of Counseling \& Development, 93(2), 163-172. doi:10.1002/j.15566676.2015.00192.x

Cross, T., \& Coleman, L. (2014). School-based conception of giftedness. Journal for the Education of the Gifted, 37(1), 94-103. doi:10.1177/0162353214521522

Elo, S., \& Kyngäs, H. (2008). The qualitative content analysis process. Journal of Advanced Nursing, 62(1), 107-115. doi:10.1111/j.1365-2648.2007.04569.x

Finnish National Board of Education (2003). National core curriculum for upper secondary schools. Helsinki, Finland: Board of Education.

Finnish National Agency for Education (2015). National core curriculum for general upper secondary schools. Helsinki, Finland: Agency for Education.

Gagné, F. (2015). Academic talent development programs: A best practices model. Asia Pacific Education Review, 16(2), 281-295. doi:10.1007/s12564-015-9366-9

Gillham, B. (2010). Case study research methods. London, England: Bloomsbury.

Haataja, E., \& Laine, A. (2017). Finnish educators' conceptions of the social-emotional needs of mathematically gifted high school students. In Dooley, T. \& Gueudet, G. (Eds.), Proceedings of the Tenth Congress of the European Society for Research in Mathematics Education (CERME10, February 1-5, 2017), (pp. 1082-1089) Dublin, Ireland: DCU Institute of Education and ERME.

Heller, K. (2013). Findings from the Munich Longitudinal Study of Giftedness and their impact on identification, gifted education and counseling. Talent Development \& Excellence, 5(1), 5164.

Kaya, F. (2015): Teachers' conceptions of giftedness and special needs of gifted students. Ted egitim ve bilim, 4O(177), 59-74. doi:10.15390/EB.2015.2885

Koichu, B., \& Andzans, A. (2009). Mathematical creativity and giftedness in out-of-school activities. In R. Leikin, A. Berman, \& B. Koichu (Eds.), Creativity in mathematics and the education of gifted students (pp. 285-308). Rotterdam, The Netherlands: Sense.

Kuusisto, E. \& Tirri, K. (2015). Disagreements in working as a team: A case study of gifted science students. Revista de Educación, 368, 279-305. doi: 10.4438/1988-592X-RE-2015-368-287

Laine, S. (2010). The Finnish public discussion of giftedness and gifted children. High Ability Studies, 21(1), 63-76. doi:10.1080/13598139.2010.488092 
Laine, S., Kuusisto, E., \& Tirri, K. (2016). Finnish teachers' conceptions of giftedness. Journal for the Education of the Gifted, 39(2), 151-167. doi:10.1177/0162353216640936

Mann, E. (2006) Creativity: The essence of mathematics. Journal for the Education of the Gifted, 3O(2), 236-262. doi:10.4219/jeg-2006-264

Mattsson, L. (2010). Head teachers' conception of gifted students in mathematics in Swedish upper secondary school. Nordic Studies in Mathematics Education, 15(3), 3-22.

Mattsson, L. (2013). Tracking mathematical giftedness in an egalitarian context (Doctoral thesis, University of Gothenburg, Sweden). Retrieved from http://hdl.handle.net/2077/34120

McHugh, M. (2006). Governor's Schools: Fostering the social and emotional wellbeing of gifted and talented students. Journal of Secondary Gifted Education, 17(3), 50-58.

McNabb, T. (2003). Motivational issues: Potential to performance. In N. Colangelo \& G. Davis (Eds.), Handbook of gifted education (3rd ed.), (pp. 417-423). Boston, MA: Allyn and Bacon.

Moon, T., \& Brighton, C. (2008). Primary teachers' conceptions of giftedness. Journal for the Education of the Gifted, 31(4), 447-480.

Movshovitz-Hadar, N., \& Kleiner, I. (2009). Intellectual courage and mathematical creativity. In R. Leikin, A. Berman, \& B. Koichu (Eds.), Creativity in mathematics and the education of gifted students (pp. 31-50). Rotterdam, The Netherlands: Sense.

Muratori, M., Stanley, J., Ng, L., Ng, J., Gross, M., Tao, T. \& Tao, B. (2006). Insights from SMPY's greatest former child prodigies: Drs. Terence ("Terry") Tao and Lenhard ("Lenny") Ng reflect on their talent development. Gifted Child Quarterly, 5O(4), 307-32. doi:10.1177/001698620605000404

Mönks, F., \& van Boxtel, H. (1985). Dyssynchrony: Uneven development. In J. Freeman (Ed.), The psychology of gifted children (pp. 275-296). New York, NY: Wiley.

Newby, P. (2010). Research methods for education. Harlow, England: Pearson Education Limited.

Persson, R. (2011). Ability climates in Europe as socially represented notability. High Ability Studies, 22(1), 79-101. doi:10.1080/13598139.2011.576086

Persson, R. (2014). The needs of the highly able and the needs of society: A multidisciplinary analysis of talent differentiation and its significance to gifted education and issues of societal inequality. Roeper Review, 36(1), 43-59. doi:10.1080/02783193.2013.856830

Pettersson, E. (2008). Hur matematiska förmågor uttrycks och tas om hand $i$ en pedagogisk praktik [How mathematical abilities are expressed and taken care of in an educational practice]. (Licentiate's dissertation). Available from Reports from MSI. (Record No. 08030)

Plucker, J. A., \& Dilley, A. (2016). Ability Grouping and the Socioemotional Development of Gifted Students. In M. Neihart, S. I. Pfeiffer, \& T. L. Cross (Eds.), The social and emotional development of gifted children: What do we know? (2nd ed.), (pp. 231-242). Waco, TX: Prufrock.

Pfeiffer, S. I., \& Burko, J. (2016). Counseling the gifted. In M. Neihart, S. I. Pfeiffer, \& T. L. Cross (Eds.), The social and emotional development of gifted children: What do we know? (2nd ed.), (pp. 243-258). Waco, TX: Prufrock.

Reis, S., \& McCoach, D. (2002). Underachievement in gifted students. In M. Neihart, S. Reis, N. Robinson, \& S. Moon (Eds.), The social and emotional development of gifted children (pp. 81-92). Washington: The National Association for Gifted Children.

Shani-Zinovich, I., \& Zeidner, M. (2009) On being a gifted adolescent: Developmental, affective and social issues. In R. Leikin, A. Berman, \& B. Koichu (Eds.), Creativity in mathematics and the education of gifted students (pp. 195-220). Rotterdam, The Netherlands: Sense. 
Speirs Neumeister, K. (2016). Perfectionism in gifted students. In M. Neihart, S. I. Pfeiffer, \& T. L. Cross (Eds.), The social and emotional development of gifted children: What do we know? (2nd ed.), (pp. 29-40). Waco, TX: Prufrock.

Stoeber, J. (2014). How other-oriented perfectionism differs from self-oriented and socially prescribed perfectionism. Journal of Psychopathology and Behavioral Assessment, 36(2), 329-338. doi:10.1007/s10862-013-9397-7

Subotnik, R., Pillmeier, E. \& Jarvin, L. (2009) The psychosocial dimensions of creativity in mathematics: Implications for gifted education policy. In R. Leikin, A. Berman, \& B. Koichu (Eds.), Creativity in mathematics and the education of gifted students (pp. 165-180). Rotterdam, The Netherlands: Sense.

Thapa, A., Cohen, J., Guffey, S., \& Higgins-D’Alessandro, A. (2013). A review of school climate research. Review of Educational Research, 83(3), 357-385. doi:10.3102/0034654313483907

Tirri, K., \& Kuusisto, E. (2013). How Finland serves gifted and talented pupils. Journal for the Education of Gifted, 36(1), 84-96. doi:10.1177/0162353212468066

Usiskin, Z. (2000). Development into the mathematically talented. Journal of Secondary Gifted Education, 11(3), 152-162.

Winkler, D., Stephenson, S., \& Jolly, J. (2012). Governor's schools: an alternative for gifted children. Gifted Child Today, 35(4), 292-295. doi:10.1177/1076217512455483

Ziegler, A., \& Phillipson, S. (2012). Towards a systemic theory of gifted education. High Ability Studies, 23(1), 3-30. doi:10.1080/13598139.2012.679085

Ziegler, A., \& Stoeger, H. (2017). Systemic Gifted Education: A Theoretical Introduction. Gifted Child Quarterly, 61(3), 183-193. doi:10.1177/0016986217705713 


\section{Appendix}

\section{Interview Framework}

\section{-Participants' professional background}

-Mathematical giftedness

-What is mathematical giftedness?

-How does mathematical giftedness develop?

-Is the development of the gifted similar to the development of others?

-Why does this special program exist?

\section{-Students of the school}

-How would you describe the students of this special program? How are they different from students of other upper secondary schools?

-How would you describe your students' social skills?

-How would you describe their emotional skills?

-Do they feel pressure because they are gifted? (Underachievement, perfectionism...)

-What are the pros and cons of associating with other mathematically oriented adolescents? Why?

-How would you describe the friendships between the students of the special mathematics program?

\section{- Teaching}

-What kind of role does an upper secondary school teacher play in the development of students' social skills?

-Does your curriculum help you support adolescents' social-emotional development? Would you like to see any changes to the curriculum?

-How would you describe encouraging and supporting students?

-To what extent do you see your (or the teachers') job as an instructor of contents or as a personal development guide [kasvatus in Finnish]?

-How central do you feel your role is as a moral educator?

\section{-Practices}

-What are the objectives of the overnight school activity? What do you do there? How does it support the social-emotional development of the students?

-What are the objectives of the Lapland summer school? What do you do there? How does it support the social-emotional development of the students?

-What are the objectives of the extra mathematics courses? What do you do there? How do they support the social-emotional development of the students?

-How does participating in mathematics competitions affect students' socialemotional development? 